\title{
Using Blackboard Collaborate for Law Pedagogy Amid a Spiraling Covid-19 Pandemic in a Historically Disadvantaged Black South African University
}

\author{
Kola O. Odeku \\ Faculty of Management and Law \\ University of Limpopo, South Africa
}

DOI: https://doi.org/10.36941/jesr-2021-0o66

\begin{abstract}
The COVID-19 continues to threaten and ravage human beings and all aspects of human existence and activities of which the educational sector is one of the hardest hit. This notwithstanding, the sector has decided to deal decisively with the various challenges such as the continuation of law pedagogy amid the pandemic. This paper emphasizes the uniqueness of providing and delivering law pedagogy predominately through online resources and tools in virtual classroom settings and spaces. The paper established that the traditional inperson, face-to-face classroom settings and spaces have been disrupted by the pandemic and as such, innovative methods of delivering law pedagogy such as the use of one of the most potent pedagogical tools, the Blackboard Collaborate $(B C)$ to conduct and deliver law modules to law students becomes imperative. This paper examines the novel system, its challenges, and prospects.
\end{abstract}

Keywords: COVID-19 Pandemic, Online resources, Blackboard Collaborate, Law pedagogy, University of Limpopo

\section{Introduction}

The manifestation and spread of the deadly Coronavirus (COVID-19) pandemic has brought about more of paradigm shift and honing of the survival instinct. Many countries have been hit more than others as the world continues to be ravaged by the deadly Coronavirus (COVID-19) (Khan et al, 2020). South Africa, the hardest hit country in Africa with the pandemic continues to experience the effects of this novel global pandemic and has recently been hit with the second wave of COVID-19 pandemic. Of note, the second wave is more deadly than the first wave because it is a new variant of the virus that spreads faster than the previous virus strain (Meldrum, 2020).

The educational sector is one of the sectors in South Africa that have been greatly negatively impacted by the pandemic due to the nation's lockdown as a measure to mitigate the spread of the virus (Mahaye, 2020). Immediately, South African government implemented social distancing to contain the spread of the virus. To this end, schools, ranging from crèche to tertiary institutions were closed and shut down in order to ensure that the spread of the virus is contained and the curve flattened. Against this backdrop, learners and students were asked to stay at homes. Mindful of the fact that Covid-19 pandemic will disrupt venue-based, in-personal, face-to-face pedagogy for a while, South African government introduced technology-based pedagogy in order to ensure that all learners and students have access to pedagogical learning materials while staying at homes. 
It is pertinent to point out that while some students have now returned to various campuses and are receiving venue-based, in-person, face-to-face pedagogy which depicts a resemblance of some sort to normal, venue-based face-to-face pedagogy may not generally occur until the year 2021 or later. The use of blended pedagogy which is "is a technology-based teaching system that integrates face-to-face teaching approach with online learning system" (Mahaye, 2020) shall continue because some students, as well as lecturers with comorbidity, are, under the University of Limpopo (UL) policy for the control and containment of COVID-18 pandemic mandated stay at home, hence the use of online resources become imperative for educational and academic activities.

Tedros Adhanom Ghebreyesus, the Director-General of the World Health Organization, said in a video message marking the Coalition's launch that "we are working together to find a way to make sure that children everywhere can continue their education, with special care to the most vulnerable and disadvantaged communities" (O'Hagan, 2020). To this end, the COVID-19 pandemic has disrupted curriculum and pedagogy in the educational sector hence the deployment and use of various online technologies and tools for pedagogy to produce outstanding learning experiences in conducive environments become imperative. It has also been observed that "that online learning is seen as a tool to address trajectories during the times of crisis, not only for survival (by communicating essential information on the fight against COVID-19) but also for teaching and learning by members of deprived communities, such as those of rural schools" (Mukuna, 2020).

These days, the majority of universities have different types of online resources and tools for pedagogy. With internet availability and advanced computing devices such as tablets, laptops, mobile phones and other digital media platforms, pedagogy is feasible anytime, anywhere and wherever and as such, universities can provide educational online delivery services to their numerous clientsstudents.

One of the potent pedagogical tools being deployed widely for effective and efficient pedagogy and which has been integrated, deployed and embraced widely at the UL is the Blackboard Collaborate (BC). The BC is an online, web-delivered system and tool within the Blackboard Learning Management System (LMS) that allows for collaborative videoconferencing sessions, students access weekly course content, announcements, and learning materials. This interactive whiteboard enables the students to interact with lecturers through discussion boards or emails. The key features of the $\mathrm{BC}$ include video and audio streaming, recording capabilities, text messaging, an interactive whiteboard, live polling and quizzes, sharing of files and applications, and breakout rooms for students to interact in small groups. According to Salam and Farooq (2020), "collaborative learning information system (WBCLIS), offers a web-based social learning environment, which facilitates collaboration between various stakeholders with technological support and pedagogical processes." Through these systems and tools, pedagogy can effectively take place for knowledge building, competency and collaboration using BC (Salam and Farooq, 2020).

It is pertinent to point out that concerning law pedagogy, generally, the legal fraternity and legal educators and scholars broadly prefer the orthodox venue-based, in-person, face-to-face methods of providing and delivering pedagogy to law students in various universities including Historically Disadvantaged Black South African Universities (HDBSAUs). The legal profession prides itself as a noble profession with standards and virtues that law students need to exhibit and display. The students learn these standards and virtues from their law lecturers who have been trained as lawyers before becoming law teachers. Most of these standards and virtues can only be taught through interaction and in personal interaction in a university setting and environment. Particularly, with regard to how students conduct themselves, punctuality to class, properly dressed to class, high ethical conducts in and outside the classrooms etcetera. All the forgoing attributes make them to be considered as fit and proper to be admitted as lawyer by the professional law bodies. However, the pandemic has now disrupted virtually all aspects of in-person pedagogies which necessitated many academic institutions to broadly embrace and integrate online systems of various types to provide and deliver pedagogies to the students.

Since the government closed down all educational institutions including universities as a safety 
measure to contain COVID-19 pandemic and continue pedagogy, the government, through the Department of Higher Education (DHE) in conjunction with tertiary institutions have been deploying various multimodal pedagogical solutions, particularly via virtual online pedagogy. They have also been working together to grapple with the complexity of providing education remotely. This is to ensure effective and efficient delivery of content and support to lecturers and in particular, law lecturers, assisting universities with the wherewithal to accomplish the new normal, providing guidance to students and their families and more importantly, addressing connectivity challenges being faced by students in accessing online pedagogy. At this juncture, equity becomes imperative bearing in mind that South African education is bedeviled with inequality and the HDBSAUs continue to face various challenges ranging from lack of funding, infrastructure, educators, etcetera. The COVID-19 pandemic has further exacerbated inequality in the educational sector in South Africa (Gustafsson and Deliwe, 2020). The pandemic and the closure of schools disproportionately impact vulnerable and disadvantaged students, especially those in the HDBSAUs.

More importantly, most of the students in HDBSAUs rely solely on various government bursaries to cover school fees, accommodation, feeding and allowance because they are from humble backgrounds and their parents are unable to afford the university fees. University closures for the HDBSAUs students could mean the loss of a vital safety net such as nutrition, protection and emotional support. The COVID-19 pandemic is not a time to deepen educational inequalities in South Africa. Rather, it is a time to invest in education's power to transform by ensuring that vulnerable disadvantaged students are not excluded but included hence providing them with all e-learning devices and tools to facilitate pedagogy (Parker et al., 2020). By doing this, it resonates perfectly with the Sustainable Development Agenda where no student is left behind or allowed to abandon studies due to COVID-19 pandemic challenges (Motala and Menon, 2020). Therefore, online pedagogy that requires the use of various expensive modern-day e-learning technologies, tools and devices, as opposed to in-person, face to face that only require class attendants and textbooks for pedagogy, is deployed, embraced and utilized (Teachonline.ca, 2020.).

\section{Methodology}

This study utilized extensive in-depth literature resources searched and derived mainly from google scholars. The majority of the literature was published online in 2020 . This is understandable because the issues and discourses about the COVID-19 pandemic are very contemporary and novel (Verma and Gustafsson, 2020). To this end, useful information from retrieved literature was used to address the problem of using BC to conduct law pedagogy amid the spiraling COVID-19 pandemic. Also, documents authored by the Information nd Communication Technology (ICT) staff of the University of Limpopo and the emails correspondence for invitation to register and be trained on how to use online technologies and in particular, the $\mathrm{BC}$ for pedagogies become critically imperatives.

\section{Literature Review}

South Africa has continued to champion massive deployment of online learning tools via network technologies throughout the academic institutions, especially the tertiary institutions (Isaacs, 2007). Hence, tools to access online resources such as computers like desktops, laptops and smartphones are being deployed for educational purposes in South Africa tertiary institutions (Aheto, 2018). Online pedagogy, in an educational context that involves the use of various online technologies to provide and deliver education (Harasim, 2017). Pre-COVID-19 pandemic, tertiary institutions in South Africa used and deployed broadly venue based, face-to-face pedagogy. However, in the midst of COVID-19 pandemic, online pedagogies have taken the front row amid the spiraling COVID-19 pandemic (Peters, 2020). While the predominantly Historically Advantaged White South African Universities (HAWSUs) are adequately equipped and have the wherewithal and financial backings together with human resources to use online technologies broadly for pedagogies, the HDBSAUs lack the human resources, 
financial leverage and viability needed to sustainably deploy and use online technologies for pedagogies.

Various reports on the quality of education at the HDBSAUs have shown the various challenges that impact the quality of the pedagogy services in these universities. The COVID-19 pandemic crisis has reaffirmed this shortcoming and exacerbated pedagogical inequality in South Africa. This notwithstanding, pedagogy still needs to continue and as such, the UL, an HDBSAU located in the rural Turfoop in the Limpopo province in South Africa decided to face the challenges and problems of COVID-19 educational lockdown and restrictions head-on with the available human and financial resources deployed and use the Blackboard for pedagogy broadly at the University. The decision to do this was taken by the management of the University under the leadership of the Vice-Chancellor \& Principal, Prof N.M. Mokgalong. It is pertinent to point out that before the COVID-19 pandemic, UL has started integrating blended pedagogy. Due to the COVID-19 pandemic, online technologies for various pedagogies are now widespread and deployed broadly. Social distancing through distance learning is in line with the government of South African's regulations which mandated mobility restrictions and limiting the number of people in any gathering to the barest minimum. When government intervened and the lockdown level was eased and universities were fully or partially opened, learners and students with comorbidity and older adults (>55 years old and above) were advised to stay at home. The UL implemented this regulation to control and contain the spread of the virus on campus while at the same time engaging responsibly in various educational and academic activities.

It is against this backdrop that the Law school at the UL has now broadly embraced the use of Blackboard for law pedagogy. It is pertinent to point out that the law profession and in particular law pedagogy at universities prides itself in using face-to-face pedagogy where the law lecturer demonstrates how a would-be lawyer needs to conduct his/herself professionally. This is said against the backdrop that law lecturers themselves are lawyers who have been certified fit and proper and it is expected that apart from law pedagogy, law students are expected to mimic and imbibe the virtue of fit and proper. There are standards of conduct that must be maintained by a law student during studies otherwise it might affect the law student from being admitted to the legal profession even if he/she passes the law degree. It now seems apparent that due to the COVID-19 pandemic online pedagogic styles would become widely used by many universities (Mukuna, 2020).

\section{Blackboard Collaborate for Law Pedagogy}

The $\mathrm{BC}$ is a synchronous, multimodal platform that has been incorporated into the UL students' lecturers' online learning experiences and is administered and managed by the ICT section of the UL (Salam and Farooq, 2020). According to Salam and Farooq (2020), "the use of collaborative learning technologies is a stimulating element of collaborative learning process, where social interaction and collaboration are key factors. Undoubtedly, the law school in UL also embraces BC because most of the pedagogies are now being conducted through multimodal using e-learning due to the spiraling COVID19 pandemic. The first step of setting up a BC in UL is for a lecturer to write a setup request email to the ICT section. For example, kindly set up a "BLACKBOARD FOR LLM MODULE (DEVELOPMENT LAW- CDLA 191)." The reply is usually: "Your request has been processed and login details are as follows:

URL zzzzzzzzzzz

Username: $\quad$ Xxxxxxxxxxx

Password: $\quad$ yyyyyyyyyy

Use firefox browser to work on Blackboard.

NB: PLEASE DO NOT DELETE THIS MAIL FOR FUTURE REFERENCE" (Boshielo, 2020).

Pursuant to the setting up of BC, the lecturer can conduct pedagogy at any time by logging in and inserting the password. The students have already been connected to the module registered and as such, all students registered for the Development Law module will have access to all the pedagogic 
activities being delivered by the lecturer on the BC.

The next step is a brief training usually delivered by the ICT on how to utilize the BC to conduct effective law pedagogy to the lecturers. The ICT has developed a training manual and uses this as the material for training lecturers. The manual details each step to take to operate the $\mathrm{BC}$ for pedagogies. On logging onto the BC, what one sees is an image depicted in Image 1, showing the panel where all pedagogic activities would be conducted and consists of the home page, course materials, submission of the module to the Blackboard, course tools, post submission of assignments, submission of assignment scripts and etcetera.

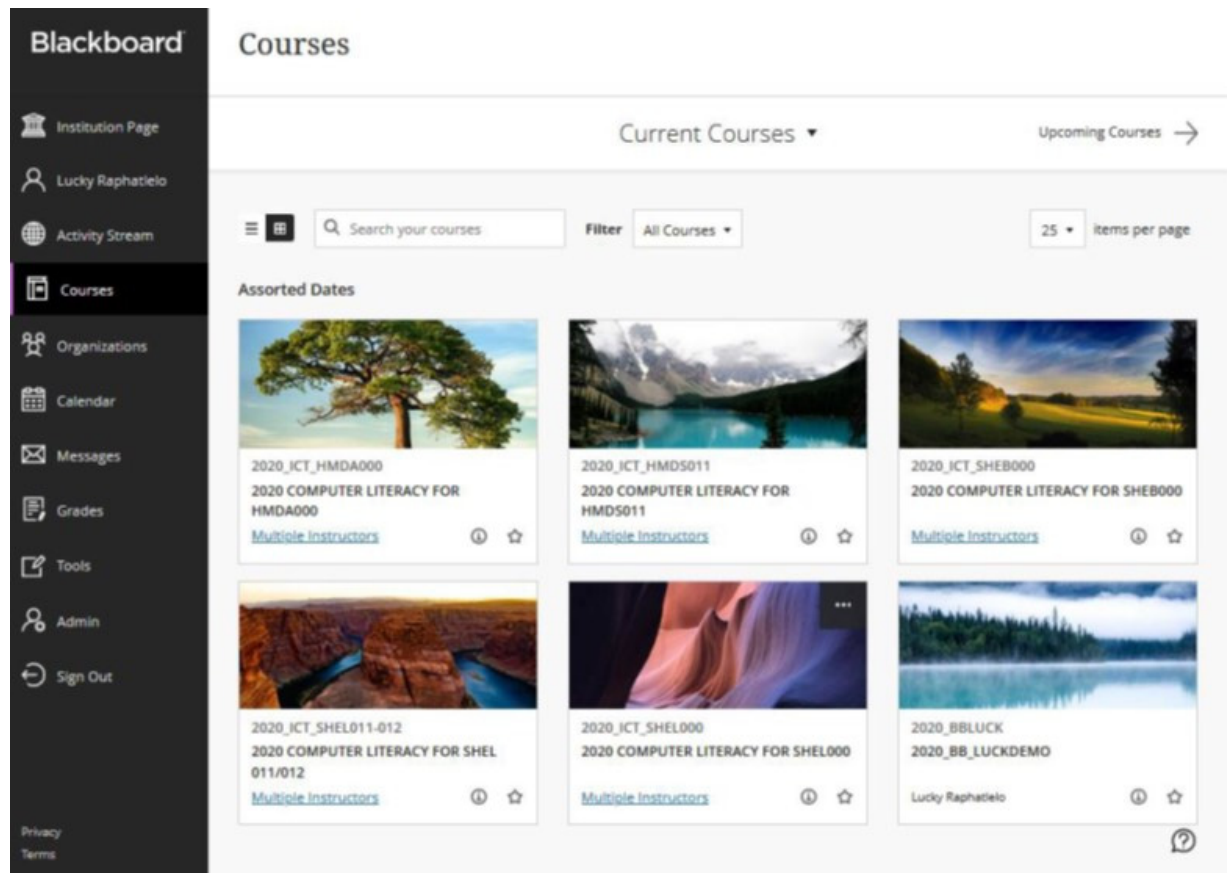

Image 1. Prepared and authored by Mokgokong C, Boshielo, A. and Raphatlelo, L. (2020). Blackboard Learn and Training, University of Limpopo, South Africa.

Generally speaking, there has been some positive feedbacks from law lecturers and students that the $\mathrm{BC}$ fosters real-time medium for feedback exchange, knowledge sharing, and virtual community building (Chen et al., 2020). The beauty of the BC is that lecturers can insist that students enable the video option and show their faces during pedagogy to monitor whether the students are paying attention and actively participating in pedagogy or not. This point is stressed in the view of the fact a student may put off the video during pedagogy, pretending that he or she is actively listening and participating whereas, engaging in other nefarious activities while pedagogy is ongoing. Also, during the COVID-19 lockdown, law students in rural and remote areas in South Africa can continue to receive quality education from UL that would make them become competent lawyers.

Another remarkable aspect of the $\mathrm{BC}$ is that law students can access lecture materials posted online by their lecturers on the BC. The law students can view the content of the materials and they can also actively participate in online discussions with their lecturers or classmates through the BC. These online pedagogic activities do not diminish the standard of law education rather it is of the same quality as what would have been received in-person, hence after their study, the law students would receive the same qualification as their counterparts in traditional, face-to-face classes on university 
campuses (Chen et al., 2020). Again, the point needs to be stressed that law pedagogy prides and believes in offering and teaching courses in face-to-face mode. However online pedagogy using BC offers and provides pedagogy opportunities and flexibility for law students who are unable to physically attend classes regularly on campus due to the COVID-19 pandemic.

At this juncture, it is pertinent to discuss how the online pedagogy using $\mathrm{BC}$ is being provided and delivered to the law students by the law lecturers. The asynchronous mode of pedagogy allows law students to access posted course materials at their convenience at any time provided that their devices are connected to the internet via a learning management system (LMS) like the BC. Similarly, concerning the synchronous mode, this mode offers law students live interaction through online web conferencing where lecturers and students interact and engage. In the words of Chen et al., (2020) "the hallmark of the synchronous delivery mode is that it is live, real-time learning which aims to replicate face-to-face instruction." Various multimodal pedagogical methods are now being deployed and use by combining both asynchronous and synchronous pedagogies delivery. During the pedagogy session, students can ask questions and receive immediate instant feedback and answer. And more importantly, interaction during pedagogy sessions is enriched through video conferencing and as such synchronous pedagogy delivery is generally considered as providing pedagogy anytime, anywhere learning.

Undoubtedly, the use of $\mathrm{BC}$ alone may fail to facilitate a sense of presence in learning situations and environments that require real-time sharing of audiovisual materials and live conversation. Undoubtedly, physical learning interactions are imperatives for law students given the requirements of the study and discipline but online pedagogy is being used effectively amid the COVID-19 pandemic. However, to a greater extent, $\mathrm{BC}$ through video-conferencing pedagogic sessions has proven to be highly interactive. Both law lecturers and law students have found the $\mathrm{BC}$ pedagogical sessions to be a flexible and convenient learning experience as they could participate from home and watch recorded sessions if necessary (Chen et al., 2020). This is why it is imperative to replicate the instructional strategies and pedagogical development capabilities of traditional classrooms where online learning environments utilize both synchronous and asynchronous platforms where students can actively engage.

\section{Challenges of Using Blackboard Collaborate for Law Pedagogy}

Despite the various benefits of the $\mathrm{BC}$, it has various challenges. Time and timing pose a major challenge. Even though it might have been generally agreed that online pedagogy shall commence at a specified time, most law students are not punctual. Some may even forget and join the virtual class midway. In a normal university setting where students are housed in hostels, there is the spirit of comradeship where students call on one another when going to attend lectures. Also, during a pedagogical session, students may experience delays in receiving feedback or responses from lecturers. Similarly, time zone differences and conflicting schedules can prevent students from attending synchronous pedagogic sessions.

What continues to be a daunting challenge is the technical difficulties experienced using $\mathrm{BC}$ for pedagogy. During pedagogy, glitches like audio problems, internet failure, malfunction microphone, electricity outage, etcetera are common and as such, they disrupt the free flow of delivery of pedagogy to law students hence most of them resort to the chat function rather than use a microphone during a live session or lecture

Lecturers' incompetency and lack of prior training are parts of the barriers to $\mathrm{BC}$ utilization in UL. Even though the ICT section of the UL has initiated and conducted BC training for lecturers, some lectures seemed to be slow in adapting to the new method of online teaching, hence affecting pedagogical delivery. Some lecturers are old-fashioned and prefer the orthodox in-person pedagogy for law students and as such, find it difficult to grapple with the online pedagogy. It is pertinent to point out that $\mathrm{BC}$ as a pedagogical tool is novel to many law lecturers in UL, hence some of them are still finding it difficult to maintain smooth incorporation of the $\mathrm{BC}$ pedagogical system. This is understandable because once a new technology is introduced into educational settings, it distorts the 
established orthodox system hence reluctance for it to be fully adopted except compelled as was done by the management of the UL. The problem is that many law lecturers are battling with how to use modern technology to achieve the educational objectives of law pedagogy. Law lecturers were trained to use textbooks bought from bookstores and those available in the university libraries and as such, they still have the orthodox belief that recommending hard copies of law textbooks to law students serves the purposes of the requirements of law pedagogy and training. This art of using instructional face to face or in-person is preferred by them when compared with the online BC pedagogy. Law lecturers have the deep belief that law pedagogy is best delivered in person, face to face rather than engaging in extra planning time to translate their lessons to the computer pedagogy environment. It has also been observed that using online pedagogy limits the law lecturer's imagination and creativity of pedagogical practices

However, the UL management has insisted on the use of online pedagogy and as such, it is incumbent on all incompetent law lecturers to embrace online pedagogy and attend all the necessary pieces of training in order to be technologically savvy in the use of online platform and systems for pedagogy (Aldubaibi, 2018).

The point is that while it is commendable that the universities have provided unhindered access to information technology, and also broadly increased training for lecturers to acquire requisite competencies to make them technologically savvy, it still appears that most of them are still struggling and have resorted to in-person pedagogy since the government has eased stringent COVID-19 lockdown in South Africa.

\section{The Role of the ICT Section of the UL in Addressing and Surmounting BC Challenges and Glitches}

Undoubtedly, due to the novelty of the broad use of online pedagogy in UL, both lecturers and students faced different challenges and technical glitches when using online pedagogy tools like the BC. However, the ICT department has provided a wide range of solutions to the university community, one of which is to provide constant training to the teaching staff in the ICT section to make them abreast of functions of online pedagogical tools and how to effectively and efficiently use them to conduct pedagogy. Although the training is voluntary, lecturers in the university are expected to enroll and be trained. It is against this that the team responsible for training in the ICT sector usually roll out invites through the university email addressed to all the university community to enroll for training. The invites are usually written with backgrounds and timetable detailing the online or $\mathrm{BC}$ training to be conducted as depicted in images 2 and 3.

Image 2. Mabitsane Abram Boshielo, (Senior Educational Technologist E-Learning Training Sessions from 10 to 28 August 2020, Fri, Aug 7, 4:25

PMhttps://mail.google.com/mail/u/o/\#search/abram.boshielo\%4oul.ac.za/FMfcgxwJXLfqrFklWWBN SWPFdGdWNVCS

"Greetings to All!

The e-Learning team will be continuing to offer training for those who still need to be introduced to some of the key features and the functionality of Blackboard (our Learning Management System) and other Tools. Below is the training schedule for the August month and please make sure that you book carefully in advance" (Boshielo, 2020).

"Note the following before you book:

1. Blackboard Intro - For all first-time Users (Prerequisite for both Collaborate \& Assessment trainings)

2. Assessment - Strictly, for those who have been trained on Introduction to blackboard

3. Collaborate - Strictly, for those who have been trained on Introduction to blackboard

4. Turnitin - This is meant for Supervisors, those who are writing papers and or generally all 
the Researchers" (Boshielo, 2020).

E-Learning Training Sessions

\begin{tabular}{|c|c|c|}
\hline \multicolumn{3}{|l|}{$10-14$ August 2020} \\
\hline ate & Morning Session (10Hoo) & Afternoon Session (14 Hoo) \\
\hline Tuesday, 11 August 2020 & TurnItIn Assignment & \\
\hline Friday, 14 August 2020 & Blackboard Online Assessment & \\
\hline \multicolumn{3}{|l|}{$17-21$ August 2020} \\
\hline Date & Morning Session (10Hoo) & Afternoon Session (14Hoo) \\
\hline Tuesday, 19 August 2020 & \multicolumn{2}{|l|}{ Introduction to Blackboard } \\
\hline \multicolumn{3}{|c|}{ Thursday, 21 August 2020 Blackboard Collaborate Ultra } \\
\hline \multicolumn{3}{|l|}{$24-28$ August 2020} \\
\hline Date & Morning Session (10Hoo) & Afternoon Session (14Hoo) \\
\hline Tuesday, 25 August 2020 & TurnItIn Assignment & \\
\hline
\end{tabular}

\begin{tabular}{|l|l|}
\hline Friday, 28 August 2020 & Blackboard Online Assessment \\
\hline
\end{tabular}

"Please click here to book. You will then receive an automated email from the system confirming your successful registration/ booking and the session joining link will be emailed to you later in the day or some hours before the actual Training.

Warm regards!" (Boshielo, 2020).

Image 3. Mabitsane Abram Boshielo, (Senior Educational technologist (e-learning) Nov 9, 2020, 3:17 PM(https://mail.google.com/mail/u/o/\#search/abram.boshielo\%4oul.ac.za/FMfcgxwKjKvblcSxxwqR nsNklKjBKTDw)

STAFF INVITATION FOR (UL-LMS)BLACKBOARD TRAININGS FOR NEW \& REFRESHER FOR NOVEMBER MONTHGreetings colleagues!

"Below is our series of LMS(Blackboard/ tmlearn) training events for everyone who has never been trained and those in need of refresher pieces of training:" (Boshielo, 2020).

E-Learning Training Sessions
\begin{tabular}{|l|l|l|} 
Date & Training & Time \\
\hline Wednesday, 11 November 2020 & Introduction to Blackboard & $10: 00$ \\
\hline Friday, 13 November 2020 & Blackboard Collaborate Ultra & $08: 30$ \\
\hline Tuesday, 17 November 2020 & Blackboard Online Assessment & $10: 00$ \\
\hline Thursday, 19 November 2020 & TurnItIn Assignment & $10: 00$ \\
\hline Monday, 23 November 2020 & Introduction to Blackboard & $11: 00$ \\
\hline Wednesday, 25 November 2020 & Blackboard Collaborate Ultra & $10: 00$ \\
\hline Monday, 30 November 2020 & Google Forms & $14: 00$ \\
\hline
\end{tabular}

"All the pieces of training will take place online (Via Collaborate tool). Please note that confirmation will be sent to your university's email address after you have registered or booked the session above later in the day or before the actual Training" (Boshielo, 2020).

"To register - please click here: https://forms.gle/F5by4zUKV6iV3omg6. 


\section{NB}

Introduction to Blackboard training: Aims at familiarization with Blackboard and at the completion of the course participants will be able to develop their own course content online.

Assessment Training: Assumes some familiarity with Blackboard. The participants will be shown how to create an online assessment using Blackboard.

Collaborate \& Turnitin - Strictly, for those who have been trained on Introduction to Blackboard.

Online questionnaire - Open to everyone who is interested in research and have the university of Limpopo s email" (Boshielo, 2020).

\section{Prospects of BC for Law Pedagogy}

An impressive aspect of online pedagogy using $B C$ is that it is purportedly convenient for both the lecturer and the students (Raish and Behler, 2018). Similarly, it provides flexible access and new methods of communication between students and lecturers (Heirdsfield et al., 2011). As most of the students are technologically savvy, online pedagogy through the use of Internet resources is essentially stimulating and appealing to a range of students (Budden, 2016). Due to constant usage, law lecturers are finding the $\mathrm{BC}$ easier to use, hence they are able to easily upload ready online pedagogical materials and resources of all types ranging from Module guidelines, content of each Module, assignment whether formative or summative, video of pre-recorded lectures, course notes, extra readings, various activities, assessment, case studies in a variety of formats, simulations and many other resources etcetera.

Law lecturers have had to embrace the changing pedagogy landscape hence law pedagogy is no more restricted to the orthodox textbooks or learning within the boundaries of the physical classroom. Virtual classroom is now the vogue and it makes sense to deploy and use his technology amid the COVID-19 pandemic (Mumtaz et al., 2020). Pre-COVID, at times, physical classrooms to conduct pedagogy is a serious challenge because the number of enrolled law students keeps increasing yearly while the classrooms are static and unable to accommodate the high number of students attending a lecture at a particular time (Palloff and Pratt, 2013). Because the space in the physical classroom is not sufficient for the increased number of las students, the use of online pedagogy becomes imperative and beneficial to pedagogy environments during and beyond the pandemic. Furthermore, the COVID-19 pandemic regulations strongly oppose the assembling or congregation of many people in space (Peters et al., 2020). Considering this, the management of UL has turned the challenge of limited space and the pandemic to an opportunity by deploying online resources for pedagogy which the member of the university-students, lecturers and staff have broadly embraced this.

Therefore, the adoption of online resources for pedagogy by the UL has Improved pedagogy because the tools and systems can be shared with a larger audience when compared to the face-to-face classroom (Istance and Paniagua, 2019). These tools supplement the traditional mode of teaching because they are essentially flexible and convenient and as such, enable students to access pedagogic materials online in their own time and at any location rather than having to commit to a specific time to engage with lecturers.

\section{Conclusion}

Overall, the online pedagogy using BC has tremendous benefits during the COVID-19 pandemic. As such, pedagogy continued despite the general lockdown of all educational institutions including universities. The massive deployment and use of online tools to conduct pedagogies at UL have helped to salvage the 2020 academic year. Presently, multimodal blended pedagogy is being deployed considering that the restrictions and lockdowns have been eased. Irrespective of the challenges and technical glitches being encountered using BC, it still preferable to no pedagogy. Law lecturers and students have had to integrate and embrace BC or pedagogy notwithstanding that traditional personal 
face to face systems they were used to are being used for virtual classrooms The ICT section of the UL has been providing all necessary assistance in form of training to lecturers to enable them to grapple the use of BC for online pedagogy. More importantly, the UL is living up to its delivery of excellent education to its various clients-students hence there has been full support given to all pedagogies resource initiatives to continue to function and deliver high standard and quality education.

\section{Recommendations}

Law lecturers must embrace this novel pedagogy environment by fully adopting online tools, especially the $\mathrm{BC}$ as a new paradigm of conducting and delivering pedagogy to law students.

It must be stressed that becoming technologically savvy to ensure effective teaching and learning at all times is imperative and entails proper planning and preparation for pedagogy environments

Presently, training is voluntary and optional at UL, it is suggested that it should be made compulsory and all lecturers and students must receive the requisite training to enable them used online pedagogy tools and resources for effective and efficient pedagogies.

\section{References}

Aheto, K. (2018).Digital Device Ownership and Learning Environment Preferences of Students in South Africa and Ghana. https://eric.ed.gov/?id=EJ1183332.

Aldubaibi, S.A.S. (2018). Understanding lecturers' pedagogic practices and perspectives in regard to blackboard utilisation in Saudi and Australian universities. https://eprints.qut.edu.au/122986/.

Boshielo, M.A. (2020). (Senior Educational technologist (e-learning). RE:SET UP BLACKBOARD FOR LLM MODULE (DEVELOPMENT LAW- CDLA 191) Mar 24, 2020, 11:51 AM. https://mail.google.com/mail/u/o/\#search/BOSHIE/QgrcJHshZZFlkgbtLrsxXSRXwJDbbvgsDkL.

Boshielo, M.A. (2020). (Senior Educational technologist (e-learning). E-Learning Training Sessions from 10 to 28 August 2020, Fri, Aug 7, 4:25 PM.https://mail.google.com/mail/u/o/\#search/abram.boshielo\%4oul.ac.za/ FMfcgxwJXLfqrFklWWBNSWPFdGdWNVCS.

Budden, R. (2016). Exploration of factors that inform curriculum studies students to use e-resources in conducting Masters of Education dissertations at a South African university.https://ukzn-dspace.ukzn.ac.za/handle/10413/15717.

Chen, J.,C., Dobinson, T., \& Kent, S. (2020). Students' perspectives on the impact of Blackboard Collaborate on Open University Australia (OUA) Online Learning 2020.. https://files.eric.ed.gov/fulltext/EJ1241569.pdf.

Fazal, R., Gary, Peters, M.A.,M., Paul, G., Radhika, G., Moon, H., ,Yoonjung, H., Lew, Z., Marie, B., Susan, R., John, Q., Justin M., Danilo, T. Ronald, B., Wang, C., Peter, M., Rima, A., Marianna, P., Nick, B., Liz, J., Pankaj, J., Kalantzis, M., Bill, C., Aslam, F.,, James, C., Greg, M., Gert, B., Petar. J., Choo, S.S., Michael, A., Stone, L., Rob, T., Marek, T., Besley, T., \& Misiaszek, L. (2020). Reimagining the new pedagogical possibilities for universities post-Covid-19: An EPAT Collective Project. https://www.tandfonline.com/doi/full/10.108o/oo131857.2020.1777655?scroll=top\&needAccess=true.

Gustafsson, M., \& Deliwe, C.N. (2020). How is the COVID-19 pandemic affecting educational quality in South Africa? Evidence to date and future risks. Stellenbosch Economic Working Papers: WP23/2020. www.ekon.sun.ac.za/wpapers/2020/wp232020.

Harasim, L. (2017). Learning theory and online technologies. Routledge, Taylor and Francis Group, New York, NY.

Heirdsfield, A., Walker, S., Tambyah, M., \& Beutel, D. (2011). Blackboard as an online learning environment: What do teacher education students and staff think? Australian Journal of Teacher Education, 36(7),1-16.

Hirsto, L., Kuusisto, E., \& Ubani, M. (2020). Exploring Educators' Challenges of Online Learning in Covid-19 at a Rural School, South Africa. International Journal of Learning, Teaching and Educational Research, 19(10), 134149 .

Isaacs, S. (2007). ICT in education in South Africa. http://documents1.worldbank.org/curated/en /612901468164380169/pdf/463640BRIoBox31cao1oICTedoSurvey111.pdf.

Istance, D., \& Paniagua, A. (2019). Learning to Leapfrog: Innovative Pedagogies to Transform Education. https://eric.ed.gov/?id=ED602937.

Khan, I., Haleem, A., \& Javaid, M, (2020). Analysing COVID-19 pandemic through cases, deaths, and recoveries. Journal of Oral Biology and Craniofacial Research. 10(4), 450-469. 
Mahaye, N. E. (2020). The Impact of COVID-19 Pandemic on South African Education:Navigating Forward the Pedagogy of Blended Learning. https://www.researchgate.net/publication/340899662_The_Impact_of_COVID19_Pandemic_on_South_African_Education_Navigating_Forward_the_Pedagogy_of_Blended_Learning.

Meldrum, A. (2020). South Africa's virus variant drives holiday surge of cases. https://ca.news.yahoo.com/southafricas-virus-variant-drives-140025441.htmlDECEMBER.

Motala, S., \& Menon, K. (2020). In search of the 'new normal': Reflections on teaching and learning during Covid-19 in a South African university. Southern African Review of Education, 26(1), 80-99.

Mumtaz, N., Saqulain, G., \& Mumtaz, N. (2020). Online Academics in Pakistan: COVID-19 and Beyond.http://www.pjms.org.pk/index.php/pjms/article/view/2894.

O'Hagan, C. (2020). UNESCO rallies international organizations, civil society and private sector partners in a broad Coalition to ensure \#LearningNeverStops. https://en.unesco.org/news/unesco-rallies-internationalorganizations-civil-society-and-private-sector-partners-broad.

Palloff, R.M., \& Pratt, K. (2013). Lessons from the virtual classroom: The realities of online teaching. Jossey-Bass, A Wiley Brand.

Parker, R., Morris, K., \& Hofmeyr, J. (2020).Education, inequality and innovation in the time of COVID-19. JET Education Services, The Education Hub, Parktown, Johannesburg, South Africa.

Peters, M.A., Rizvi, F., McCulloch, G., \& Gibbs, P. (2020). Reimagining the new pedagogical possibilities for universities post-Covid-19: An EPAT Collective Project.https://www.tandfonline.com/doi/full/10.108o/oo131857.2020.1777655.

Raish, V., \& Behler, A. (2018). Library connection: an interactive, personalized orientation for online students. Journal of Library \& Information Services in Distance Learning, 13(2), 129-149.

Salam, M., \& Farooq, M.S. (2020). Does sociability quality of web-based collaborative learning information system influence students' satisfaction and system usage? https://doi.org/10.1186/s41239-020-00189-z.

Teachonline.ca 2020. A New Pedagogy Is Emerging... and Online Learning Is a Key Contributing Factor. https://teachonline.ca/tools-trends/how-teach-online-student-success/new-pedagogy-emerging-andonline-learning-key-contributing-factor.

Verma, S., \& Gustafsson, A. (2020). Investigating the emerging COVID-19 research trends in the field of business and management: A bibliometric analysis approach. Journal of Business Research, 118, 253-261. 